\title{
Treatment of patent ductus arteriosus with ibuprofen
}

Bart Van Overmeire, Ingrid Follens, Suzanne Hartmann, Wouter L Creten, Karel J Van Acker
Department of Paediatrics, Division of Neonatology, University Hospital of Antwerp, Wilrijkstraat 10, B 2650 Edegem, Antwerp, Belgium B Van Overmeire

I Follens

S Hartmann

K J Van Acker

Department of Biomedical Physics W L Creten

Correspondence to: Dr Bart Van Overmeire.

Accepted 14 January 1997

\begin{abstract}
Aim-To evaluate the efficiency and side effects of ibuprofen for the early treatment of patent ductus arteriosus (PDA)and compare it with indomethacin.

Methods-Forty preterm infants with gestational ages of less than 33 weeks, with respiratory distress syndrome (RDS) and echocardiographically confirmed PDA, were randomly assigned at days 2 to 3 of life to receive either intravenous indomethacin $3 \times 0.2 \mathrm{mg} / \mathrm{kg}$ at 12 hour intervals or intravenous ibuprofen $1 \times 10$ $\mathrm{mg} / \mathrm{kg}$, followed by $5 \mathrm{mg} / \mathrm{kg} 24$ and 48 hours later.

Results-PDA closed in 15 of 20 patients from the indomethacin group $(75 \%)$ and in 16 of $20(80 \%)$ from the ibuprofen group. Seven patients (three indomethacin, four ibuprofen) required a second treatment with indomethacin and in five (three in the indomethacin group and two in the ibuprofen group) the duct was ultimately ligated. Ibuprofen patients had a better urinary output and showed no increase in serum creatinine concentrations compared with the indomethacin group. Ibuprofen was not associated with any other side effect.

Conclusions-Ibuprofen treatment seems to be as efficient as indomethacin in closing PDA on the third day of life in preterm infants with respiratory distress syndrome and seems to have fewer renal side effects.
\end{abstract}

(Arch Dis Child 1997;76:F179-F184)

Keywords: patent ductus arteriosus; respiratory distress syndrome; ibuprofen; indomethacin; Doppler echocardiography

The incidence of patent ductus arteriosus (PDA) in very low birthweight infants with respiratory distress syndrome (RDS) is about $40 \%$ on the third day of life. ${ }^{12}$ Left to right shunting through a PDA causes several undesirable pulmonary, haemodynamic, renal and gastrointestinal effects and increases the risk of intraventricular haemorrhage and bronchopulmonary dysplasia. Therefore, treatment of PDA in preterm neonates with RDS is indicated before important left to right shunting occurs. ${ }^{3}{ }^{4}$

Although indomethacin is effective in closing PDA, ${ }^{1-6}$ its use may be associated with complications such as decreased cerebral, gastrointestinal, and renal blood flow, gastrointestinal perforation or haemorrhage and altered platelet function..$^{7-13}$ Some side effects such as oliguria, anuria, and transient renal failure are common. ${ }^{14-16}$ Ibuprofen, another non-steroidal anti-inflammatory drug, can also close the ductus arteriosus in animals, without affecting intestinal haemodynamics. ${ }^{17} 18$ It further enhanced cerebral blood flow autoregulation and exhibited some neuroprotective effect following oxidative stress in the animal model. ${ }^{19-21}$ When ibuprofen was administered in preterm neonates in early postnatal life, a reduced incidence of PDA was observed. ${ }^{22}$

As no comparative trials are available, we wanted to examine whether ibuprofen is as efficient as indomethacin in closing PDA, but with fewer side effects. We report the results of a prospective randomised study comparing the effectiveness and the side effects of ibuprofen and indomethacin in the treatment of PDA in preterm infants with RDS.

\section{Methods}

The study was conducted in the neonatal intensive care unit of the University Hospital of Antwerp, Belgium. Neonates admitted to the unit were eligible for enrolment if the following criteria were met : (1) gestational age below 33 weeks; (2) RDS treated with mechanical ventilation (intermittent positive pressure ventilation (IPPV) or high frequency oscillatory ventilation (HFOV) with additional oxygen requirements above $30 \%$; (3) postnatal age between 48 and 72 hours. Neonates with major congenital malformations including congenital heart defect, persistent pulmonary hypertension of the newborn, or hydrops fetalis, or in whom either indomethacin or ibuprofen were contraindicated, were excluded. Contraindications for treatment with either drug were: (1) recent (less than 48 hours) intraventricular haemorrhage; (2) clinical bleeding tendency as revealed by haematuria, blood in the gastric aspirate or in the stools, blood in the endotracheal tube aspirate, oozing from venous or capillary puncture sites; (3) thrombocyte count of less than $60000 / \mathrm{mm}^{3}$; (4) oliguria of less than $1 \mathrm{ml} / \mathrm{kg} / \mathrm{h}$ during the preceding eight hours; (5) blood urea nitrogen in excess of 14 $\mathrm{mmol} / \mathrm{l}$, serum creatinine concentration in excess of $140 \mu \mathrm{mol} / 1$; (6) hyperbilirubinaemia for which exchange transfusion was required.

Daily clinical care was performed by attending neonatologists who did not take part in the study. All infants were nursed on open tables for the first 36 to 48 hours of life and then transferred to humidified incubators during 
the remaining study period. Fluid intake was primarily guided by body weight, serum sodium concentrations, and serum osmolarity. A weight loss of $5-10 \%$ was allowed for during the first postnatal days. Most patients received one or more transfusions of packed red blood cells or plasma. For RDS treatment, surfactant replacement therapy (Alvofact, Boehringer or Survanta, Abbott) was applied in doses of 100 $\mathrm{mg} / \mathrm{kg}$ according to a strict protocol.

Informed consent was obtained from the parents and the study was approved by the medical ethics committee of the hospital.

In all patients eligible for enrolment in the study, a complete echocardiographic-Doppler evaluation was performed to visualise the PDA and the shunting through it (Hewlett Packard Sonos 1500 with $7.5 \mathrm{MHz}$ transducer; examinations were recorded on videotape and printouts). The internal ductal diameter was registered as the average of four measurements in colour Doppler mode with the same preand post processing settings. ${ }^{23}$ The maximal velocity of the left to right shunt through the ductus was recorded by pulsed or continuous Doppler and the ratio of left atrial to aortic root diameter measured in M-mode was registered. Shunting through the PDA was arbitrarily graded as follows: (1) minor shunting if a small jet was detectable at the pulmonary end of the ductus with colour flow and continuous or pulsed Doppler interrogation, with the proviso that no disturbed flow was detectable at the level of the pulmonary valves and diastolic forward flow in the pulmonary trunk was absent, and if the left atrial to aortic ratio was less than 1.2; (2) moderate shunting if a disturbed diastolic flow was easily detectable at all sites of the pulmonary trunk, a diastolic back flow was present in the aorta immediately beneath the PDA and a forward flow above the PDA; (3) severe shunting if a diastolic back flow was detectable in the aorta and if dilatation of the left atrium was present and expressed as a left atrium to aortic root ratio above 1.6. The maximal velocity of the ductal left to right shunt was noted in order to obtain an estimate of the systemic to pulmonary arterial pressure difference. When there was minor shunting or when the patient showed substantial improvement of his respiratory status during the second day of life, a delay of 24 hours was allowed to see if the patient could be weaned off the respirator. If not, the echocardiographic Doppler ultrasound scan was repeated and if the patient still had PDA s/he was entered.

Enrolled patients were randomised using the sealed envelope technique to receive either intravenous indomethacin (Indocid) three times $0.2 \mathrm{mg} / \mathrm{kg}$ at 12 hourly intervals, or intravenous ibuprofen (Ibuprofen-lysine) 10 $\mathrm{mg} / \mathrm{kg}$ followed by $5 \mathrm{mg} / \mathrm{kg}$ after 24 and 48 hours. Both drugs were continuously infused over 15 minutes. The doses and intervals for ibuprofen were chosen in accordance with the recommendations in infants and neonates which are based on preliminary pharmacodynamic data and on the in vitro comparison of the cyclo-oxygenase type 1 isoenzyme inhibitory potencies of different NSAIDs. ${ }^{24-26}$
A second echocardiographic Doppler ultrasound scan was performed in all patients after the last dose of the randomised treatment regimen and at the age of 7 days to evaluate the ductus as defined earlier. When PDA was still present and the patient was still on mechanical ventilation, $s /$ he was treated with indomethacin $(3 \times 0.2 \mathrm{mg} / \mathrm{kg}$ at 12 hourly intervals). Another echocardiographic-Doppler scan was performed either after the second treatment to assess its efficiency, or after one week in the patients who received only one treatment, in order to detect a possible late reopening of the ductus.

Clinical and biological data were prospectively reported on data sheets designed for this study. The following parameters were registered.

(1) Clinical parameters: date and time of birth, gestational age, sex, antenatal corticosteroid or indomethacin administration, findings on physical examination at the time of echocardiography, grade of RDS, ventilator settings, time, type, dose and number of surfactant administrations, daily crystalloid and colloid fluid intake, urinary output and daily body weight. Bleeding tendency was evaluated using the same criteria as those for contraindications to treatment. Intravenous fluid intake was expressed in $\mathrm{ml} / \mathrm{kg}$ of birthweight rather than actual daily weight. Similarly, urine output was expressed in $\mathrm{ml} / \mathrm{kg}$ of birthweight /hour.

(2) Laboratory parameters: serum creatinine, serum electrolytes, serum osmolarity, glycaemia, haematocrit and haemoglobin concentration, thrombocytes, $\mathrm{C}$ reactive protein, white cell count and differentiation and cultures when there was suspicion of infection.

(3) Cranial ultrasound scans: these were performed on all infants on days 1,2, and 3 and weekly thereafter; if clinically relevant additional ultrasound scans were also performed. Haemorrhages were graded as mild, moderate, or severe according to Shankaran. ${ }^{27} 28$

(4) Outcome: in the surviving patients this was defined on the basis of their respiratory support (mean airway pressure, inspired oxygen concentration) on postnatal days 7 and 14, the total number of days on mechanical ventilation and on additional oxygen, the numbers of patients still on additional oxygen on day 28, the time needed to regain birthweight and the time interval between birth and full enteral feeding.

Statistical hypothesis analysis involved the use of $\chi^{2}$ test on contingency tables, the standard $t$ test for independent samples, and paired comparisons test for repeated measurements. For evaluation of non-parametric data the Mann-Whitney U test was used. As our first aim was to detect a clinical difference in the efficiency of ibuprofen compared with indomethacin of at least $30 \%$ with $\mathrm{P}=0.05$ and a power of $80 \%$, ibuprofen otherwise not offering any advantage over spontaneous closure, 20 patients were included in each group. Computer software used was CSS-Statistica. 
Table 1 Patient characteristics before treatment *

\begin{tabular}{|c|c|c|}
\hline Characteristic & Indomethacin $(n=20)$ & Ibuprofen $(n=20)$ \\
\hline Birthweight (g) & $1210(360)$ & $1270(450)$ \\
\hline Gestational age (weeks) & $28.7(1.9)$ & $29.0(2.4)$ \\
\hline \multicolumn{3}{|l|}{ Maternal medication: } \\
\hline Corticosteroids & $9(45)$ & $10(50)$ \\
\hline Indomethacin & $7(35)$ & $8(40)$ \\
\hline \multicolumn{3}{|l|}{ Ventilatory support (hours): } \\
\hline \multicolumn{3}{|l|}{ Mean MAPt $\left(\mathrm{cm} \mathrm{H}_{2} \mathrm{O}\right)$} \\
\hline 24 & $9.1(2.9)$ & $9.0(2.9)$ \\
\hline 48 & $9.0(3.8)$ & $8.6(2.7)$ \\
\hline 72 & $7.8(2.9)$ & $8.3(2.8)$ \\
\hline \multicolumn{3}{|l|}{ Mean $\mathrm{FIO}_{2}(\%)$} \\
\hline 24 & $50(17)$ & $44(13)$ \\
\hline 48 & $41(17)$ & $43(14)$ \\
\hline 72 & $34(12)$ & $40(17)$ \\
\hline Surfactant treated & $19(95)$ & $15(75)$ \\
\hline \multicolumn{3}{|l|}{ Intraventricular haemorrhage: } \\
\hline Mild & 1 & 2 \\
\hline Moderate & 1 & 1 \\
\hline Severe & 2 & 0 \\
\hline \multicolumn{3}{|l|}{ PDA evaluation: } \\
\hline \multicolumn{3}{|l|}{ Shunt: } \\
\hline Moderate & 11 & 12 \\
\hline Large & 9 & 8 \\
\hline Ductal diameter (mm) & $2.5(0.7)$ & $2.6(0.7)$ \\
\hline LA:Ao ratio & $1.57(0.20)$ & $1.57(0.21)$ \\
\hline Age at treatment (days) & $3.1(0.5)$ & $3.2(0.4)$ \\
\hline
\end{tabular}

* Values expressed as mean (SD) or number (\%)

$\dagger$ Mean airway pressure.

q Left atrial to aortic root diameter.
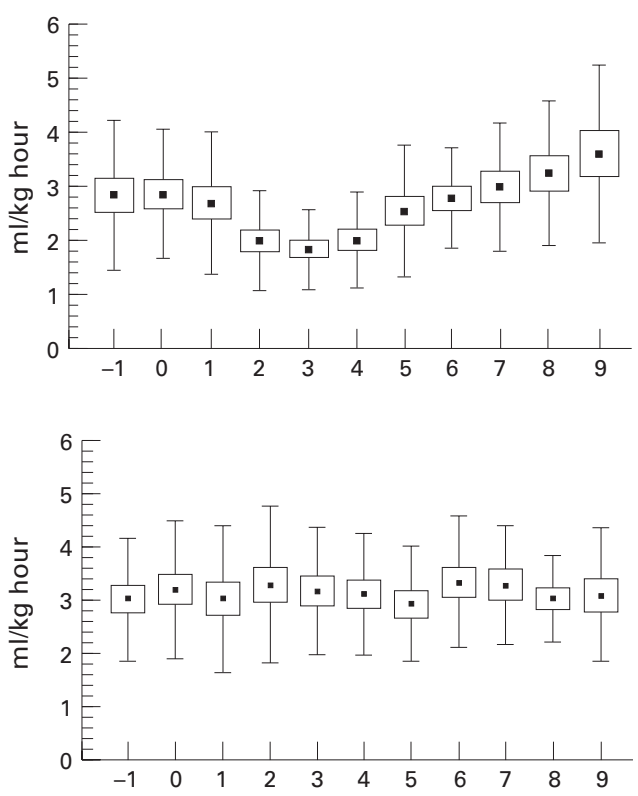

Figure 1 Urine production in the indomethacin group (upper panel) and the ibuprofen group (lower panel) over 11 days. Day $0=$ start of treatment; means $\pm 1 S E, \pm 1$ $S D$. There was a significant difference between the two groups on days 2,3 , and $4(P=0.002)$.

Eighty five patients were eligible for entry in the study and underwent an echocardiographic-Doppler ultrasound evaluation between the second and third day of life. Forty five were excluded because of an already closed duct in $40(47 \%)$, PDA with minor shunting and respiratory improvement in two, severe right to left shunting through the ductus due to pulmonary hypertension in two, and sepsis with bleeding tendency in one patient. The remaining 40 patients had PDA and were randomly allocated to receive either indomethacin or ibuprofen.

The characteristics of the patients before treatment are shown in table 1: there were no significant differences between either group. The respiratory status of the patients is expressed by their need for ventilatory support (average mean airway pressure and mean percentage of supplemental oxygen at 24,48 , and 72 hours of life) and the number of patients that received exogenous surfactant treatment. There were no patients with minor shunting or a ductal diameter of less than 1.5 $\mathrm{mm}$ at entry.

INCIDENCE OF PDA AND TREATMENT

There was no significant difference in efficiency of either treatment, the closing rate being $75 \%$ and $80 \%$ in the indomethacin and ibuprofen groups, respectively. In nine patients the ductus arteriosus remained open after the first treatment (five in the indomethacin group and four in the ibuprofen group). Two of these, both from the indomethacin group, received no further treatment for PDA because of a substantial improvement in their respiratory status to spontaneous ventilation. Seven (three in the indomethacin group, four in the ibuprofen group) received a second treatment with indomethacin, on average on the 8.3 (2.2) ( \pm 1 SD) day of life. The efficiency of this backup treatment was 29\%: closure of the PDA occurred in only two of the seven patients (one in each group). These seven patients had the lowest birthweights of the whole group (birthweight 940 (200) g, gestational age 27.3 (2.3) weeks). Ultimately, the duct was ligated in five patients, on average on day 11 (three from the indomethacin group and two from the ibuprofen group). In one patient the duct reopened after initial closure with ibuprofen treatment and failure of a second dose of indomethacin. In the nine patients with persistent ductus after the first treatment the maximal velocity of the ductal left to right shunt increased from 1.41 to $1.93 \mathrm{~m} /$ second $(\mathrm{P}=0.03)$ and the left atrium to aortic root ratio decreased from 1.56 to 1.37 $(\mathrm{P}=0.02)$ without significant differences between either group of patients.

\section{RENAL FUNCTION}

In the indomethacin group urine output decreased significantly on the second day after start of treatment to a minimal mean value of $1.9 \mathrm{ml} / \mathrm{kg}$ birthweight/hour $(\mathrm{P}=0.001)$ and increased again afterwards in all infants within seven days. But there was no significant decrease in urine output after start of treatment in the ibuprofen group (fig 1). Urine output was significantly less in the indomethacin group than in the ibuprofen group on days 2, 3, and 4 after treatment $(\mathrm{P}=0.002)$. In the ibuprofen group urine production varied from $3.0 \mathrm{ml} / \mathrm{kg}$ birthweight/hour on the day before treatment to $3.3 \mathrm{ml} / \mathrm{kg}$ birthweight/hour on day 7 after treatment. As to the number of patients with oliguria (urine production less than $1 \mathrm{ml} / \mathrm{kg} /$ hour), $40 \%$ developed oliguria in the indomethacin group compared with $5 \%$ in the ibuprofen group $(\mathrm{P}=0.02)$. The increase in serum creatinine was larger after indomethacin treatment, reaching a maximum mean value of $1.25 \mathrm{mg} / 100 \mathrm{ml}$ on the third day after 

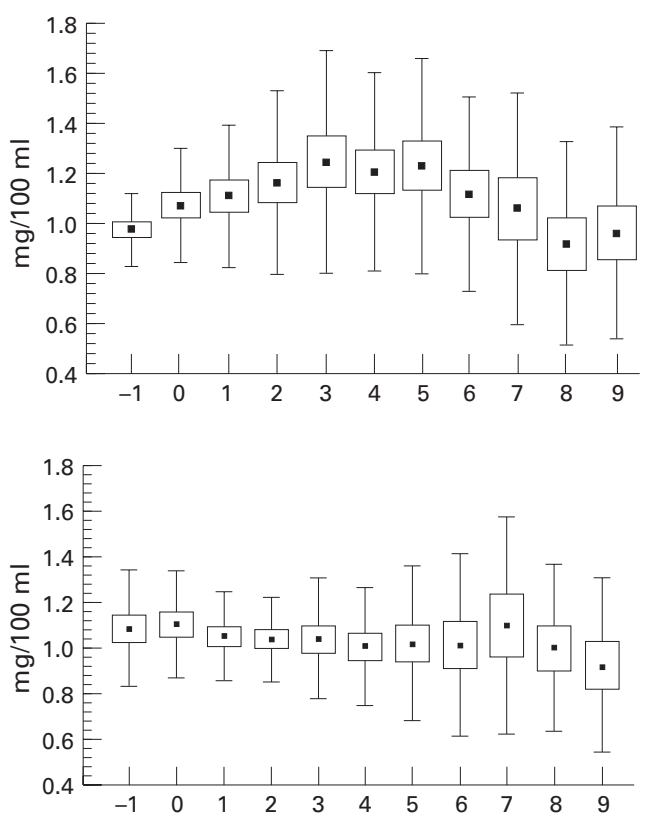

Figure 2 Serum creatinine concentration in the indomethacin group (upper panel) and the ibuprofen group (lower panel) over 11 days. Day $0=$ start of treatment; means $\pm 1 S E \pm 1 S D$. Maximal difference between the two groups occurred on day $3(P=0.07)$.

treatment, whereas no significant difference was seen in the ibuprofen group ( $\mathrm{P}=0.07$ ) (fig 2). Diuretics were not used in either group during the first week of life. Daily fluid intake did not differ significantly between both patient groups. The starting rate of crystalloid intake depended on birthweight: patients with birthweights $\leqslant 1000 \mathrm{~g}$ were given $100-110 \mathrm{ml} / \mathrm{kg} /$ day, patients with birthweights $>1001 \mathrm{~g}$ received 60-75 $\mathrm{ml} / \mathrm{kg} /$ day. Crystalloid fluid intake was increased day by day for both

Table 2 Respiratory and cardiovascular evaluation *

\begin{tabular}{|c|c|c|c|}
\hline Characteristic & Indomethacin $(n=20)$ & Ibuprofen $(n=20)$ & Difference \\
\hline \multicolumn{4}{|l|}{ Ventilatory support: } \\
\hline \multicolumn{4}{|l|}{ Mean MAP† $\left(\mathrm{cm} \mathrm{H}_{2} \mathrm{O}\right)$} \\
\hline Day 7 & $6.0(0.8)$ & $6.0(0.6)$ & $0.0(1.0)$ \\
\hline Day 14 & $4.0(0.8)$ & $4.8(1.1)$ & $-0.8(1.4)$ \\
\hline \multicolumn{4}{|l|}{ Mean $\mathrm{FIO}_{2}(\%)$} \\
\hline Day 7 & $32.4(4.0)$ & $27.1(1.4)$ & $5.3(4.2)$ \\
\hline Day 14 & $29.6(3.5)$ & $30.6(4.6)$ & $-1.0(5.8)$ \\
\hline Days on ventilator & $14.1(2.3)$ & $15.5(3.4)$ & $-1.4(4.1)$ \\
\hline Days on additional oxygen & $32(6)$ & $47(8)$ & $-15(10)$ \\
\hline \multicolumn{4}{|l|}{ PDA evaluation: } \\
\hline Closure $(\%)$ & $15(75)$ & $16(80)$ & $-1(5)$ \\
\hline Diameter $\$(\mathrm{~mm})$ & $1.9(0.2)$ & $1.7(0.3)$ & $0.2(0.4)$ \\
\hline LA:Ao ratio & $1.26(0.04)$ & $1.23(0.04)$ & $0.03(0.06)$ \\
\hline \multicolumn{4}{|l|}{ Backup treatment for PDA: } \\
\hline Indomethacin & 3 & 4 & -1 \\
\hline Ligation & 3 & 2 & 1 \\
\hline
\end{tabular}

* Values expressed as mean (SE) or number (\%).

$\dagger$ Mean airway pressure.

$\int$ Of persistent ducts after first treatment, indomethacin $n=5$, ibuprofen $n=4$.

ๆ Left atrial to aortic root diameter.

Table 3 Other outcome variables *

\begin{tabular}{llll}
\hline Characteristic & Indomethacin $(n=20)$ & Ibuprofen $(n=20)$ & Difference \\
\hline Deaths (\%) & $3(15)$ & $1(5)$ & $2(10)$ \\
Sepsis (\%) & $4(20)$ & $5(25)$ & $-1(-5)$ \\
Necrotising enterocolitis (\%) & $1(5)$ & $1(5)$ & 0 \\
Age to regain birthweight (day) & $20.2 \pm 1.9$ & $16.1 \pm 1.7$ & $4.1 \pm 1.6$ \\
Retinopathy of prematurity (\%) & $1(5)$ & $0(0)$ & $1(5)$ \\
\hline
\end{tabular}

* Values expressed as mean (SE) or numbers (\%).

No significant differences were observed for any item. patient groups to about $120 \mathrm{ml} / \mathrm{kg} /$ day by day 10 of life. There was no difference between the groups for the use of colloids or blood products. Daily weight evolution was similar in both treatment groups, with an average weight loss of $7 \%$.

RESPIRATORY FUNCTION

The incidence and severity of RDS were not significantly different between the two treatment groups. The average mean airway pressure and mean fraction of inspired oxygen concentration following PDA treatment was not different in the groups, although a trend toward higher oxygen need was observed in the indomethacin group. Data are given for days 7 and 14 of life (table 2). The number of days on ventilation, the number of days on additional oxygen, and the number of patients that still had additional oxygen requirements on the 28 th postnatal day did not significantly differ between the two groups. At the age of 28 days, three patients were still being ventilated and nine still needed supplemental oxygen in the indomethacin group compared with four and 13, respectively, in the ibuprofen group. There were no differences in air leak syndromes or pulmonary haemorrhages between the groups.

OTHER VARIABLES

No difference in bleeding tendency, as defined earlier, was observed. Occult blood in the stools was detected in four patients (two in each group). Microscopic haematuria was frequently noted during the first two to three days of life, but its incidence was equal in both groups. No difference was observed in platelet count, bilirubinaemia, or hepatic enzyme values.

No significant differences in sepsis or other infectious complications could be demonstrated (table 3). Bowel perforation was observed in one patient in each group: both had been exposed prenatally to indomethacin. Two other patients had necrotising enterocolitis. There were four neonatal deaths: three in the indomethacin group (major intraventricular haemorrhage, overwhelming sepsis, and intractable respiratory deterioration) and one in the ibuprofen group (intractable respiratory deterioration).

No adverse effect of ibuprofen on feeding tolerance was observed; the time to regain birthweight was in fact somewhat shorter in this group, but this difference was not significant. The time interval needed to be exclusively enterally fed, was comparable in both groups. In the indomethacin group, one patient developed retinopathy of prematurity.

\section{Discussion}

For many years indomethacin has been the drug of choice in the treatment of PDA but renal and cerebral haemodynamic side effects have been frequently reported. ${ }^{1-16}$ Strategies to minimise the renal side effects such as its association with furosemide, or with low doses of dopamine or the use of prolonged low doses, have not all been equally successful. ${ }^{29-32}$ Other NSAIDs have also been tried but either had 
other side effects, as is the case with mefenamic acid,,$^{33}$ or were less efficient in closing the duct, as was shown for aspirin. ${ }^{35}$

In animals ibuprofen closed the duct more or less as well as indomethacin and had fewer cerebral and gastrointestinal side effects. ${ }^{17-19}$ Some early studies are available in the human neonate from which it was concluded that ibuprofen is efficient at closing the duct and has less cerebral and renal side effects. ${ }^{36-40}$ More recently its prophylactic use within the first few hours after birth has been advocated ${ }^{22}$ : the prophylactic treatment of PDA is, however, not yet uniformly accepted. ${ }^{41}$ The present study is the first which compares the two drugs in a prospective randomised way. We found that ibuprofen as an early treatment of PDA in preterm neonates with RDS, is as efficient as indomethacin and, unlike indomethacin, is not associated with significant side effects, particularly decreased urinary output or increased serum creatinine. The dose of ibuprofen was based on its in vivo inhibitory effect on cyclo-oxygenase $1 .^{26}$ Although more pharmacokinetic data on ibuprofen are needed in neonates, it has been suggested that it should be administered at longer time intervals than indomethacin ${ }^{24}$ : therefore, dosing intervals of 24 hours were chosen.

The ductal closure rate after either treatment was within the range reported, but lower than we reported earlier. ${ }^{35}$ This may be due to an increased prenatal use of indomethacin in the patients from the present study which was comparable in both groups (table 1).

The capacity to close definitively the duct and arrest all flow through the ductal lumen is the main effect of successful PDA treatment. However, reduction of shunting through the duct will also result in a substantial decrease in the pulmonary blood flow and, through this, may lead to a reduction of the lung water content and to an improvement in RDS. We therefore compared the degree of ductal shunt in both groups of treated neonates. Not only was there no difference in closure rate, but the degree of shunting through the duct was also identical in the nine patients from both groups with a still open duct. Indomethacin may increase pulmonary vascular resistance, but as we observed a decrease in the pulmonary artery pressure $v s$ systemic pressure, with no differences in either groups, this could be excluded, at least in our patients whose duct remained open. Cardiovascular evaluation of patients who did not need a second treatment because of substantially improved respiratory status, was no different between the groups. As temporary closure and reopening of the duct has been reported as being associated with severe infection and sepsis, ${ }^{42}$ we investigated this in our patients: the incidence of confirmed or probable sepsis was comparable in both groups; reopening in two patients from the ibuprofen group was not associated with infection (table 3).

We cannot explain the difference in renal side effects between the two drugs. One possibility is that both drugs inhibit the cyclooxygenase enzyme system in the neonatal kidney to a different extent. In vitro, in the doses used in this study, both drugs inhibit the cyclo-oxygenase system to the same extent. ${ }^{26}$ Very little, however, is known about the expression of isozymes in neonatal renal tissue. Another possibility is that, due to different pharmacokinetic characteristics in the neonate, serum indomethacin concentrations remained high enough to influence both the ductus and the renal function, whereas those of ibuprofen were sufficiently high to close the duct but lacked the potential to impair renal function. Finally, the possibility of non-prostaglandin effects should also be considered.

Other side effects of ibuprofen treatment, such as increased bleeding tendency, need for backup treatment, or feeding intolerance, were not observed. There was, on the other hand, a trend towards earlier regain of birthweight and full oral feeding in the ibuprofen group. Our study was not designed to measure cerebral haemodynamics: less impairment of the latter compared with indomethacin, has been reported. ${ }^{38-40}$

From these preliminary data we conclude that ibuprofen can be used efficiently in premature neonates with RDS for the closure of the ductus arteriosus on the third day of life, with the advantage that it causes fewer side effects than indomethacin. Our findings need to be confirmed by studying a larger number of patients. Other possible side effects should also be investigated.

1 Clyman RI. Medical treatment of patent ductus arteriosus premature infants. In: Long WA, ed. Fetal and Neonatal Cardiology. Philadelphia: WB Saunders, 1990:682-90.

2 Ellison RC, Peckham GJ, Lang P, Talner NS, Lerer TJ, Lin L. Evaluation of the preterm infant for patent ductus arteriosus. Pediatrics 1983;71:364-72.

3 Cotton RB, Stahlman MT, Bender HW, Graham TP, Catterton WZ, Kovar I. Randomized trial of early closure of symptomatic patent ductus arteriosus. $\mathscr{f}$ Pediatr of symptomatic

4 Stefano JL, Abbasi S, Pearlman SA, Spear ML, Esterly KL, Bhutani VK. Closure of the ductus arteriosus with indomethacin in ventilated neonates with respiratory distress syndrome; effects on pulmonary compliance and ventilation. Am Rev Respir Dis 1991;143:236-9.

5 Gersony WM, Peckham GJ, Ellison RC, Miettinen OS, Nadas AS. Effects of indomethacin in premature infants with patent ductus arteriosus: results of a national collaborative study. F Pediatr 1983;102:895-906.

6 Clyman RI. Recommendations for the postnatal use of indomethacin: An analysis of four separate treatment strategies. F Pediatr 1996;128:601-7.

7 Edwards AD, Wyatt JS, Richardson C, Potter A, Cope M, Delpy DT. Effects of indomethacin on cerebral haemodynamics in very preterm infants. Lancet 1990;335:1491-5.

8 Van Bel F, Van de Bor M, Stijnen T, Baan J, Ruys JH. Cerebral blood flow velocity changes in preterm infants after a single dose of indomethacin: duration of its effect. Pediatrics 1989;84:802-7.

9 Coombs RC, Morgan MEI, Durbin GM, Booth IW, McNeish AS. Gut blood flow velocities in the newborn: effects of patent ductus arteriosus and parenteral indomethacin. Arch Dis Child 1990;65:1067-71.

10 Van Bel F, van Zoeren D, Schipper J, Guit GL, Baan J. Effect of indomethacin on superior mesenteric artery blood flow velocity in preterm infants. I Pediatr 1990;116:965-70.

11 Van Bel F, Guit GL, Schipper J, van de Bor M, Baan J. Indomethacin-induced changes in renal bloodflow velocity waveform in premature infants investigated with color Doppler imaging. F Pediatr 1991;118:621-6.

12 Wolf WM, Snover DC, Leonard AS. Localized intestinal perforation following intravenous indomethacin in premature infants. $\mathcal{F}$ Pediatr Surg 1989;24:409-10.

13 Friedman Z, Whitman V, Maisels MJ, Berman WJr, Marks $\mathrm{KH}$, Vessell ES. Indomethacin disposition and indomethacin-induced platelet dysfunction in premature infants. F Clin Pharmacol 1978;18:272-9.

14 Mahony L, Carnero V, Brett C, Heymann MA, Clyman RI. Prophylactic indomethacin therapy for patent ductus arteriosus in very-low-birth-weight infants. $N \mathrm{Engl} f \mathrm{Med}$ 1982;306:506-10 
15 Cifuentes RF, Olley PM, Balfe JW, et al. Indomethacin and renal function in premature infants with persistent patent renal function in premature infants with p

16 Seyberth HW, Rascher W, Hackenthal R, Wille L. Effect of prolonged indomethacin therapy on renal function and selected vasoactive hormones in very-low-birth weight infants with symptomatic ductus arteriosus. 7 Pediat 1983;103:979-84.

17 Coceani F, White E, Bodach E, Olley PM. Age dependent changes in the response of the lamb ductus arteriosus to oxygen and ibuprofen. Can $\mathcal{f}$ Physiol Pharmacol 1979;57:825-31.

18 Grosfeld JL, Kamman K, Gross K, Cikrit D, Ross D, Wolfe M. Comparative effects of indomethacine, Prostaglandine E1 and ibuprofen on bowel ischemia. Pediatr Surg 1983;18:738-42.

19 Chemtob S, Laudignon N, Beharry K, Rex J, Varma D, Wolfe L. Effects of prostaglandins and indomethacin on cerebral blood flow and oxygen consumption of conscious newborn piglets. Dev Pharmacol Ther 1990;14:1-14.

20 Chemtob S, Beharry K, Rex J, Varma DR, Aranda JV. Prostanoids determine the range of cerebral blood flow tanoids determine the range of cerebral blood flow

21 autoregulation of newborn piglets. Stroke 1990;21:777-84. domethacin compromises hemodynamics during positive pressure ventilation, independently of prostanoids. $\mathcal{f} A p p l$ Physiol 1993;74:1672-8

22 Varvarigou A, Bardin CL, Beharry K, Chemtob S, Papageorgiou A, Aranda JV. Early ibuprofen administration to prevent patent ductus arteriosus in premature newborn infants. FAMA 1996;275:539-44.

23 Kluckow M, Evans N. Early echocardiographic prediction of symptomatic patent ductus arteriosus in preterm infants undergoing mechanical ventilation. $f$ Pediat 1995;127:774-9.

24 Aranda JV, Varvarigou N, Beharry K, Modanlou H, Bottolli I, Bardin C. Pharmacokinetics of intravenous ibuprofen in premature newborns. Pediatr Res 1994;35;81A.

25 Kauffman RE, Nelson MV. Effect of age on ibuprofen pharmacokinetics and antipyretic response. 7 Pediatr macokinetics and

26 Meade EA, Smith WL, DeWitt DL. Differential inhibition of prostaglandin endoperoxide synthase (cyclooxygenase) isozymes by aspirin and other non-steroidal antiinflammatory drugs. 7 Biol Chem 1993;268:6610-4

27 Shankaran S, Slovis TLS, Bedard MP, Poland RL Sonographic classification of intracranial hemorrhage: a prognostic indicator of mortality, morbidity and shortterm neurologic outcome. F Pediatr 1982;100:469-75.

28 Shankaran S, Cepeda E, Muran G, Mariona F, Johnson S, Kazzi SN, et al. Antenatal phenobarbital therapy and neonatal outcome i: effect on intracranial hemorrhage. Pediat rics 1996;97:644-8.
29 Yeh TF, Wilks A, Singh J, Betkerur M, Lilien L, Phildes RS Furosemide prevents renal side effects of indomethacin therapy in preterm infants with persistent ductus arteriosus. F Pediatr 1982;101:433-7.

30 Fajardo CA, Whyte RK, Steele BT. Effect of dopamine on failure of indomethacin to close the patent ductus arteriosus. F Pediatr 1992;121:771-5.

31 Rennie JM, Cooke RWI. Prolonged low dose indomethacin for persistent ductus arteriosus of prematurity. Arch Dis Child 1991;66:55-8.

32 Hammerman C, Aramburo MJ. Prolonged indomethacin therapy for the prevention of recurrences of patent ductus

33 Sakhalkar VS, Merchant RH. Therapy of symptomatic patent ductus arteriosus in preterms using mefenemic acid and indomethacin. Indian Pediatr 1992;29:313-8.

34 Fujiwara T. Closure of PDA with mefenamic acid. In: Robertson B, Van Golde LMG, eds. Pulmonary surfactant. Amsterdam: Elsevier Science Publishers, 1984:495.

35 Van Overmeire B, Brus F, Van Acker KJ, Van Der Auwera JC, Schasfoort M, Elzenga NJ. Aspirin versus indomethacin treatment of patent ductus arteriosus in the preterm neonate with respiratory distress syndrome. Pediatr Res 1995;38:886-91.

36 Aranda JV,Varvarigou N, Beharry K, Modanlou H, Bardin C, Papageorgiou A. The effect of early intravenous ibuprofen on renal function in premature newborns. Pediatr Res 1994;37:361A.

37 Van Overmeire B, Follens I, Hartmann S, Mahieu L, Van Reempts P. Intravenous ibuprofen for the treatment of patent ductus arteriosus in preterm infants with respirapatent ductus arteriosus in preterm infants with

38 Patel J, Marks K, Roberts J, Azzopardi D, Edwards AD. Effect of indomethacin and ibuprofen on cerebral haemodynamics and oxygenation during treatment for patent ductus arteriosus (sPDA) in preterm infants. Pediatr Res 1995;38:448A.

39 Patel J, Marks KA, Roberts I, Azzopardi D, Edwards AD. Ibuprofen treatment of patent ductus arteriosus. Lancet 1995;346:255.

40 Mosca F, Bray M, Lattanzio M, Fumagalli M, Colnaghi MR, Compagnoni G. Comparison of the effects of indomethacin (INDO) and ibuprofen (IBU) on cerebral perfusion and oxygenation in preterm infants. Pediatr Res 1996;39:231A.

41 Fowlie PW. Prophylactic indomethacin: systematic review and meta-analysis. Arch Dis Child 1996;74:F81-F7.

42 Gonzalez A, Sosenko IRS, Chandar J, Hummler H, Claure $\mathrm{N}$, Bancalari E. Influence of infection on patent ductus arteriosus and chronic lung disease in premature infant weighing 1000 grams or less. F Pediatr 1996;128:470-8. 